\title{
Barataria, un cruce de caminos: entre la oralidad y la escritura
}

\author{
Jesús Botello*
}

Sabemos, porque Cervantes lo dice en su Quijote, que Sancho Panza es un completo analfabeto, como él mismo declara cándidamente en la novela en siete ocasiones: «yo no he leído ninguna historia jamás, porque ni sé leer ni escribir» (I, 10; 114), «como yo no sé leer ni escrebir» (I, 10; 118), «no sé la primera letra del abecé» (I, 26; 297), «Pues a fe mía que no sé leer» (I, 31; 364), «yo no sé leer ni escribir, puesto que sé firmar» (II, 36; 931), «letras pocas tengo porque aún no sé el abecé» (968), «no sé leer ni escribir... bien sé firmar mi nombre» (II, 43; 976). En cambio, el caballero es un hidalgo altamente alfabetizado, «un texto en sí mismo». En este sentido, la crítica cervantina ha puesto de relieve las dispares matrices culturales de la inmortal pareja. James A. Parr señala que, a pesar de que en Don Quijote Cervantes privilegie la escritura, la oralidad «is quite literally there from the outset, informing writing, reading it aloud, invading its domain, parodying it» (171). Elias L. Rivers destaca como el diálogo es el epicentro de la novela y descansa en la dialéctica fraguada entre un «intense reader of literature, who talks in a bookish style, and an illiterate rustic, who speaks the substandar Spanish of a rich oral culture (113). En suma, éste sea quizá el principal punto de conflicto - la crítica lo ha puesto de relieve - entre amo y criado: ambos pertenecen a culturas de naturaleza dispar ${ }^{1}$. El escudero se sabe diferente a su amo, le guar-

* University of Chicago.

1. La oralidad y su aplicación al Quijote han sido objeto de una nutrida atención crítica en los últimos años. Véase «Literatura oral y ficción cervantina», del hispanista francés Maxime Chevalier, donde dicho estudioso analiza con detalle los cuentecillos tradicionales y dibuja las principales influencias que la oralidad dejó en la obra de Cervantes. En su opinión «Cervantes mucho más debe a las sugerencias de la literatura oral que a "las fuentes librescas librescas que con tanto empeño y tan moderado éxito hemos buscado"» (196). Otro cervantista galo, Michel Moner, profundiza en las 
da gran respeto, porque es el representante de la escritura, lo supuestamente superior. Esta actitud, sin embargo, irá cambiando a lo largo de la novela, y Cervantes mostrará a un Sancho cada vez más astuto y orgulloso de su oralidad, porque sabe que Don Quijote, aun con tantas lecturas a sus espaldas, no puede competir con la palabra hablada. (Este dialogismo cultural por otra parte es lógico en una obra publicada cuando todavía la nueva tecnología «no había suplido por completo a la oralidad como principal medio de difusión cultural» [Martín Morán 338], y en el que los índices de analfabetismo en España y Europa seguían todavía siendo muy elevados) ${ }^{2}$. Tal vez el punto álgido de esta supremacía de lo oral sean las tres sentencias que Sancho dicta en su recién adquirida ínsula.

Este trabajo examina los juicios de Sancho en su gobierno baratario, probando cómo son un ejemplo de la supremacía de la oralidad sobre la escritura en Don Quijote, y una crítica cervantina a la ineficacia de un sistema judicial sobresaturado con la escritura. Ante la justicia desalmada de la época y las innumerables trabas que la escritura trajo a la sociedad, Don Quijote presenta la oralidad como un ejemplo para los hombres: rodeado de personajes anclados en la letra impresa, Sancho aparecerá como un modelo de eficacia y diligencia, y sus sapientísimos juicios serán símbolos de la vuelta a la Edad de Oro.

En la segunda parte de la novela, el gobernador Sancho debe dictar sentencia en tres pleitos que le plantean: las caperuzas, el báculo con los escudos en su interior y la mujer presuntamente violada. En principio, no podría esperarse demasiadas luces por parte de un campesino sin educación formal, puesto

diferentes maneras en que la oralidad puede percibirse en los textos cervantinos. En su opinión, la obra de Cervantes «a été égalment profondément marqué par les strategies narratives et les techniques de dynamisation des conteurs» (309). Así, técnicas como la del cuento de nunca acabar, las oportunas interrupciones que dejan al espectador deseoso de escuchar el resto de la historia o los capítulos que no coinciden con lo narrado apuntan a técnicas procedentes de la tradición oral. Por su parte, apoyándose en teóricos como Walter J. Ong y Jack Goody, José Manuel Martín Morán propone que el Quijote fue publicado en período en el que «aún la escritura no había suplido por completo a la oralidad como principal medio de difusión cultural» (338). Partiendo de esta base, este investigador propone que la locura de don Quijote se debe principalmente a la práctica de la lectura silenciosa, peligrosa para Alonso Quijano pues procedía de un entorno oral. Es decir, el hidalgo no pudo asimilar el impacto provocado por el consumo masivo de estos «perniciosos libros». Incluso desarrolla una hipótesis plausible sobre los tan traídos descuidos cervantinos. Plantea que si en realidad «la obra cervantina estaba destinada en un principio a la difusión oral, habría que replantear la cuestión de los descuidos bajo esa nueva perspectiva». (21) Para Montero Reguera, esto es conjeturar demasiado, y así afirma que aunque existe un cierto residuo oral en el Quijote, lo cierto es que «la oralidad no permite explicar tales posibles descuidos cervantinos» (70). Por último, debe mencionarse a Margit Frenk y María Rosa Lida de Malkiel, cuyos pertinentes trabajos sobre la oralidad y el cuento popular en el Siglo de Oro sentaron una sólida base sobre la que se desarrollaron posteriores estudios.

2. Sara Nalle apunta que, a lo largo del siglo XVI, los índices de analfabetismo disminuyeron paulatinamente. Esto fue debido en parte al auge de las universidades y los colegios mayores, a la difusión de la imprenta y el menor costo de los libros. Según dicha autora, el índice de analfabetismo masculino en España era similar e incluso menor al de otros países europeos. En Castilla, a mediados del XVI, un $69 \%$ de los madrileños podía firmar su nombre. En Toledo, por ejemplo, los archivos de los casos inquisitoriales revelan que, entre 1601 y 1650, un $62 \%$ de los hombres podía firmar. Sobre el mismo período, en Cuenca, y de nuevo basándose en archivos de la inquisición, un 52\% de los hombres declaraba poder leer (69). 
que anteriormente Sancho ha sido retratado tanto por el narrador como por otros personajes de la novela como un tonto ${ }^{3}$. Sin embargo, Sancho resuelve los pleitos efectivamente bien, y ríos de tinta han corrido intentando explicar cómo un analfabeto puede resolver enigmas de tan difícil resolución.

Anteriores trabajos han arrojado luz sobre el difícil problema. Algunos han interpretado las resoluciones de Sancho desde una óptica carnavalesca, suponiendo que Barataria debe enmarcarse en la noción de «mundo al revés» típico del carnaval. Para Augustin Redondo, esta inversión de papeles aclararía el sabio proceder de Sancho, que actuaría como el loco sabio, por cuya boca «pueden expresarse las verdades divinas» (49). Otros las han explicado atribuyéndolas al conocimiento tradicional del campesino, vinculándolas a este saber popular del «tonto listo» (Molho 248). Por último, tampoco ha faltado quien las atribuya a una incoherencia del propio Cervantes, que quiso que Sancho triunfara en unos casos que no podía conocer, por pertenecer a una tradición erudita (Chevalier 71). Según Chevalier, «ni la pregunta ni las sentencias pertenecen a la tradición oral, y tres pleitos de los cuatro proceden conocidamente de fuentes escritas: la carrera del gordo y del flaco de la Floresta española, el báculo de los escudos de algún florilegio de exempla, la mujer violada del Norte de los estados de fray Francisco de Osuna» (70). Por tanto, «es extraño que triunfara la agudeza de Sancho en unas sentencias de índole erudita, en unos casos que mal podía conocer un analfabeto». De este modo, según Chevalier «el personaje de Sancho [muestra] falta de coherencia» (71).

\section{LA ESCRITURA EN LA PARED}

Los pleitos que debe resolver Sancho son, sin duda alguna, ciertamente difíciles. Sin embargo, el escudero triunfa sobre juicios que procedían de la cultura escrita, tal como apuntaba Chevalier en su estudio. Así, desde el principio del episodio, el narrador establece con claridad meridiana la oposición entre la oralidad del gobernador y la escritura de los personajes de la esfera de los duques. Es lo primero en lo que se hace hincapié: «En tanto que el mayordomo decía esto a Sancho, estaba él mirando unas grandes y muchas letras que en la pared frontera de su silla estaban escritas, y como él no sabía leer, preguntó que qué eran aquellas pinturas que en aquella pared estaban» (I, 45; 992). El mayordomo de los duques se encarga de descifrar el enigma: «Señor, allí está escrito y notado el día en que vuestra señoría tomó posesión desta ínsula, y dice el epitafio: "Hoy día, a tantos de tal mes y de tal año, tomó la posesión desta ínsula el señor don Sancho Panza, que muchos años la goce"» (I, 45; 992). Este pasaje esconde una referencia que la crítica ha pasado inexplicable-

3. Así lo describe por primera vez el narrador: «En este tiempo solicitó don Quijote a un labrador vecino suyo, hombre de bien [...] pero de muy poca sal en la mollera» (I, 7; 91). Ya en Barataria, se recalca de nuevo el aspecto de bodoque de Sancho: «El traje, las barbas, la gordura y pequeñez del nuevo gobernador tenía admirada a toda la gente que el busilis del cuento no sabía» (II, 45; 992). 
mente por alto. En el Antiguo Testamento, se cuenta la historia del rey Baltasar, hijo de Nabucodonosor. La historia es conocida, pero interesa recordarla. Baltasar era conocido por su afición a la bebida y por su espíritu pusilánime. Así, en mitad de una gran fiesta dada por Baltasar mientras los ejércitos persas y medos sitiaban la ciudad, el rey, bajo los efectos del vino, mandó traer los vasos que su padre Nabucodonosor había expoliado del templo de Jerusalén. Dios «habló» mediante la escritura, y una mano apareció y escribió unos extraños signos en la pared. El rey, sin embargo, no pudo entender las palabras escritas, así que buscó en toda Babilonia a quien pudiese descifrar el mensaje, ofreciendo valiosas dádivas a la persona que pudiese descifrar el mensaje ${ }^{4}$. Finalmente, el rey, aconsejado por su mujer, hizo llamar al joven Daniel, que sí pudo interpretar el texto. El mensaje que Dios había cifrado en la pared decía: «MENE, MENE, TEKEL, UPARSIN, PERES», y la traducción que hizo Daniel del texto fue: Mené: Dios ha medido tu reino y le ha puesto fin; Tequel: has sido pesado en la balanza y encontrado falto de peso; Parsín: tu reino ha sido dividido y entregado a los medos y los persas ${ }^{5}$. Esa misma noche Baltasar fue muerto, su puesto ocupado por Darío el Meda, y de este modo terminó sus días el imperio de Babilonia.

La interpretación del texto bíblico ha sido un enigma crítico para los estudiosos de todas las épocas, por varias razones, pero, sobre todo, porque la lectura correcta de la inscripción se dificulta por los conflictos que el propio texto contiene. En primer lugar, es necesario saber a qué hacen referencia los oscuros vocablos mene, mene, tekel, uparsin. Clermont-Ganneau en 1885 fue el primer investigador en sugerir que las palabras hacen referencia a unidades monetarias de la época. Aunque brillante, para Frank Zimmermann (1965) esta explicación no guarda relación alguna con el núcleo central de la predicción de Daniel, la caída de Babilonia. Por su parte, J. Marquart ofrece una visión un tanto peregrina del tema, pues establece un paralelo entre la visión de Baltasar de la escritura en la pared y la visión que tiene Heliodoro de un jinete montado a caballo, vestido con armadura de oro y guarnecido con un riquísimo arnés (2 Mac. 3.25). Por último, Zimmermann, llevando a cabo un estudio lingüístico de los vocablos del oráculo, señala cómo cada una de las palabras proferidas por Daniel porta multitud de acepciones, cuyos fines son maravillar y confundir al espectador. Consecuentemente, resulta harto difícil establecer un significado único. Este hecho, unido a la disparidad de las interpretaciones críticas del episodio bíblico ponen de relieve su cualidad esencial: su desconcertante ambigüedad. Seguramente fue esa la principal razón que llevó a Cervantes a enmarcar sutilmente el episodio de Barataria mediante la narración bíblica, que funcionaría como subtexto, según la terminología de Genette.

4. «Quicumque legerit scripturam hanc et interpretationem eius manifestam mihi fecerit, purpura vestietur et torquem auream habebit in collo et tertius in regno meo dominabitur» (Dan. 5.7).

5. «[M]ane, numeravit Deus regnum tuum et complevit illud; thecel, appensus es in statera et inventus es minus habens; phares, divisum est regnum tuum et datum est Medis et Persis» (Dan. 5.26-28). 
El episodio de la escritura divina en la pared era bien conocido desde la Edad Media; en esta época, las representaciones de la figura de Baltasar lo muestran casi como una prefiguración del Anticristo $^{6}$. A partir del Renacimiento, el contenido teológico del episodio fue decayendo, al tiempo que aumentó el interés por su carácter dramático y espectacular, y este último sentido es el que prima en la recreación cervantina ${ }^{7}$. Gracias a esa referencia bíblica puede entenderse la ironía de Cervantes al recrear el suceso, ironía que de otra manera podría pasar desapercibida, puesto que en realidad la anécdota descrita antes en Barataria (la pregunta de Sancho y la respuesta del mayordomo de los duques) es una reescritura de la leyenda del monarca y el suceso contado en la Biblia. Cervantes recogió la historia bíblica y la reformuló, trastocando los términos y readaptándolos para que encajasen bien en la burla de Barataria. En primer lugar Sancho Panza, al igual que Baltasar, es un bebedor empedernido y un glotón de primera. Lo importante para nuestro estudio, sin embargo, es que es incapaz de leer lo escrito sobre la pared, y es el mayordomo de los duques el que debe resolver el enigma, y lo hace así: «hoy día, a tantos de tal mes y de tal año, tomó la posesión desta ínsula el señor don Sancho Panza, que muchos años la goce» (I, 45; 992).

Por otra parte, llama la atención el paralelismo entre el honesto comportamiento de Daniel y Sancho. Éste juega astutamente con el doble sentido de dones como «fórmula de tratamiento» y como «regalos», lo que remite invariablemente al rechazo del profeta de los «dones», esto es, los «regalos» que el rey de Babilonia ofreció a Daniel. El primero rechaza rotundamente los regalos - los dones - que Baltasar le ofrece como recompensa por resolver el acertijo, mientras que Sancho, en un alarde de virtud, al oírse mentar de don por el mayordomo de los duques, recuerda sus orígenes humildes y reparte la primera lección de humanidad en su gobierno: «[Q]ue yo no tengo don, ni en todo mi linaje le ha habido: Sancho Panza me llaman a secas, y Sancho se llamó mi padre, y Sancho mi agüelo, y todos fueron Panzas, sin añadiduras de dones ni donas» (I, 45; 992).

Además, aunque ambiguo, el texto bíblico ha conseguido transmitir un mensaje diáfano: lo perecedero de los afanes humanos y, en particular, de los imperios y sus gobernantes ${ }^{8}$. Para un crítico perspicaz como Zimmermann, la

6. Así sucede por ejemplo en el Ordo Prophetarum (procesión de los profetas), un ciclo de misterios medieval muy popular en la época, asociado a la llegada del Mesías, lo que podría asociarse con la llegada de Sancho a Barataria.

7. Calderón de la Barca dedicó a la figura de Baltasar un auto sacramental titulado La cena del rey Baltasar (1634). En el arte pictórico, el mismo tema sirvió, años después, de inspiración a pintores de la talla de Rembrandt Harmenszoon van Rijn, cuyo tratamiento del tema es un clásico, El festín del rey Baltasar (1635), o Domenico Fiasella en El festín de Baltasar (16??)

8. Simon Schama, exegeta de la obra de Rembrandt, comenta sobre El festín de Baltasar lo siguiente: «[F]iel al mensaje bíblico, Rembrandt sugiere lo frágil de las cosas: los metales preciosos, los placeres del apetito, la longevidad de los imperios» (418). Por otra parte, es curioso el parecido físico entre el Baltasar imaginado por Rembrandt, orondo y con cara de simple, y la imagen estereotípica que tenemos de Sancho, también gordo y con cierto aire de bobalicón, con una punta de vicioso. 
actitud de Baltasar al conocer la interpretación propuesta por Daniel es cuanto menos sorprendente: cree al joven adivino judío sin ningún género de duda, lo cual es sumamente extraño. ¿No podía haber puesto en tela de juicio lo expuesto por Daniel, o al menos haber pedido algún tipo de explicación? Aún más notable es el hecho de que Baltasar no haga ningún tipo de preguntas acerca de la mano que aparece repentinamente. ¿A quién pertenece? ¿Cómo puede una mano amputada escribir? En lugar de hacerse estas preguntas - lógicas sin duda - el monarca se muestra aterrorizado ante la escritura en la pared, lo cual no tiene demasiado sentido ya que, como la misma historia relata, no podía entender lo que allí se decía. ¿Es que acaso no podía ser una buena nueva? Quizá, como sugiere Zimmermann, Baltasar sabía lo que aquellos extraños signos en la pared significaban o, al menos, albergaba una ligera sospecha (207). Su pecaminoso proceder — se había entregado a todo género de vicios, expoliado nada menos que los vasos del templo de Salomón- le haría necesariamente presagiar que su reinado tenía los días contados. Lo mismo barrunta Sancho, cuya fina intuición le dice que con toda probabilidad su régimen baratario será efímero: «si el gobierno me dura cuatro días». Sólo ansía que sus augurios no se cumplan, para que le dé tiempo a erradicar el funesto tratamiento de don... «yo escardaré estos dones» (II, 45; 993). Desgraciadamente, tal y como el lector colige por la brevedad del imperio de Baltasar, el de Sancho no durará si quiera esos cuatro días.

Existe sin embargo una diferencia fundamental entre ambas historias. En la Biblia lo escrito supuestamente procedía de Dios, era la palabra de Jehová, y debía cumplirse. La escritura bíblica es, en definitiva, veraz, y el rey Baltasar fue asesinado esa misma noche9. En Barataria, sin embargo, la índole de lo escrito toma un cariz absolutamente distinto. La expresión que traduce el ayudante a Sancho y que dice «que muchos años la goce» es ilusoria, puesto que sabemos que el gobierno de Sancho tiene los días contados desde el mismo momento en que vio la luz. Los duques fueron los responsables de esa «pintura» que Sancho no puede comprender y, podría decirse, por tanto, que son espejos invertidos de Dios. De este modo, por un lado, tendríamos las Sagradas Escrituras, que son la palabra de Dios, y por el otro, las letras burlonas de los duques, que son el triste reflejo de las primeras.

Esta interpretación, sin embargo, no agota otras muy posibles; porque podemos ir un poco más allá, apurar los significados menos aparentes y descubrir así un poderoso paralelismo entre ambos motivos: la mano amputada que escribe en la pared recuerda simbólicamente a la manquedad del propio Cervantes. De este modo, podríamos pensar que los verdaderos escritores/ autores son Dios y Cervantes/narrador; junto a ellos, aparecen representados los problemas y las dudas asociados al proceso de la escritura y a la inter-

9. Calderón de la Barca dedicó a la figura de Baltasar un auto sacramental titulado La cena del rey Baltasar (1634). En el arte pictórico el mismo tema sirvió, años después, de inspiración a pintores de la talla de Rembrandt Harmenszoon van Rijn, cuyo tratamiento del tema es un clásico, Belshazzar 's Feast (1635), o Domenico Fiasella en El festín de Baltasar (16??). 
pretación de los textos literarios, que, como es sabido, asoman con asiduidad en las páginas del Quijote ${ }^{10}$. Esa castración sugerida por la aparición de la mano sesgada del resto del cuerpo prefigura el castigo sufrido por Baltasar y Sancho - los tormentos a los que será sometido en su gobierno- y, por asociación, en el caso del Quijote, remite también a la limitación y a la falsedad aparejadas a la escritura ${ }^{11}$.

\section{Los JUICIOS DE SANCHO}

Justo después de esta importante escena que marca el tono del episodio, Sancho debe resolver el primer pleito, el de las caperuzas. Antes de entrar de lleno en el primer juicio, debe señalarse que hay dos elementos en el texto que apuntan hacia un entorno oral. En primer lugar, en todos los juicios los litigantes hablan por sí mismos. En ninguno de los pleitos a los que asiste Sancho en Barataria hace acto de presencia la figura del abogado. Para Martin T. Clanchy, esto se debe al énfasis que durante mucho tiempo se le dio a la palabra hablada, a pesar del creciente uso de documentos escritos. «Before the development of authenticated documents, courts were most reluctant to allow a litigant to be represented in his absence [...] The assumption was that where possible a litigant must speak on his own behalf in court, because only words from his own mouth were authentic» (énfasis mío, 221). En los tres pleitos que Sancho resuelve en Barataria: las caperuzas, el báculo con los escudos en su interior y la mujer presuntamente violada, todos los litigantes se encargan ellos mismos de su defensa legal, tal y como Clanchy describe para la Inglaterra medieval. Esto es así porque hasta tiempo después de la imprenta la introducción paulatina de la «marea» escritural hizo que la antigua defensa de viva voz se considerase en ocasiones como un acto peregrino, extrañamente anticuado. Es decir, la escritura, como afirma Clanchy, «shifted the emphasis in testing truth from speech to documents» (222). Al mismo tiempo, la importancia de la escritura en el episodio es palpable, pues el mismo Sancho afirma tras la resolución de la paradoja del puente y el ahorcado que «esto lo diera firmado de mi nombre si supiera firmar», lo que indica que Sancho, a pesar de su analfabetismo, sabía con toda seguridad de la existencia de documentos escritos que se debían firmar, con el fin de otorgarles legitimidad ${ }^{12}$.

10. En efecto, tanto en la Biblia como en Barataria encontramos tres instancias narrativas: un emisor del mensaje (Dios-Cervantes), un receptor (Baltasar-Sancho) y un intérprete (Danielmayordomo).

11. En realidad, esta historia bíblica debe asociarse más bien al episodio de las Tablas de la Ley, narrado en Éxodo. En los dos episodios, el Padre impone su ley a los hombres a través de la palabra escrita.

12. No obstante, debe recordarse que cuando la duquesa le preguntó quién había redactado la carta dirigida a Teresa Panza, Sancho le había confesado que aunque él no había podido hacerlo: «[Y] o no sé leer ni escribir», orgullosamente puntualizó que sabía autentificar documentos: «puesto que sé firmar» (931). Capítulos más tarde, antes de partir hacia Barataria, un melindroso Don Quijote le 
Tras haber escuchado atentamente, el recién nombrado gobernador habla en voz alta y pronuncia estas palabras: «Paréceme que en este pleito no ha de haber largas dilaciones, sino juzgar luego a juicio de buen varón», y dicta sentencia: «yo doy por sentencia que el sastre pierda las hechuras, y el labrador el paño, y las caperuzas se lleven a los presos de la cárcel, y no haya más» (II, 45; 994). Sancho se muestra diligente y eficaz, y lo que quiere decir con «juzgar a juicio de buen varón» es que no acudirá a leyes escritas, sino a su «natural virtud» (Castro 204). Desligado de la letra, Sancho es capaz de dilucidar la cuestión, porque su palabra hablada tiene un poder «casi mágico». Según Walter Ong, en las culturas existe un tipo de conocimiento distinto al libresco, que permite aprehender la realidad de una forma más profunda. «Human beings in primary oral cultures, those untouched by writing in any form, learn a great deal and possess and practice great wisdom, but they do not «study» (9). Otro investigador, Malinowski, apunta en la misma dirección de Ong, recalcando además la íntima asociación entre palabra hablada y actuación en las culturas orales, donde a la primera se la considera investida de poderes casi mágicos $(451,470-81)$. Es decir, para el iletrado gobernador, las palabras son actos, y no la figuración simbólica del mundo ${ }^{13}$. Como consecuencia de esto, hablar es actuar, y es hacerlo en un marco de referencia concreto, de ahí su diligencia al resolver el pleito. En definitiva, la palabra hablada es sinónimo de poder, y su enunciación, equivale a la enunciación de un acto de hechicería, tal y como ocurre en las culturas orales.

Por otra parte, las «maravillosas sentencias» de Sancho, como las llamó Américo Castro, se asemejan mucho al modo de impartir justicia de los musulmanes de la época, que Cervantes ciertamente admiró, por estar muy cercano al concepto humanista de la virtud natural del hombre, cuyo elogio hallamos en Montaigne y otros pensadores del XVI. En un célebre pasaje de El Amante liberal, donde se encarece la justicia musulmana, se dice:

Entraron a pedir justicia, así griegos cristianos como algunos turcos, y todos de cosas de tan poca importancia, que las más despachó el cadí sin

reprochaba a Sancho que no supiera leer ni escribir. «Gran falta es la que llevas contigo, y, así, querría que aprendieras a firmar si quiera». La respuesta del escudero es esclarecedora: «Bien sé firmar mi nombre, que cuando fui prioste en mi lugar aprendí a hacer unas letras como de marca de fardo que decían que decía mi nombre». ¿Qué hara entonces Sancho cuando las encumbradas responsabilidades en Barataria lo obliguen a firmar? «Fingiré que tengo tullida la mano derecha y haré que firme otro por mí, que para todo hay remedio, si no es para la muerte». Como sabemos, a Sancho no le hace falta firmar para imponer su sano juicio en los distintos pleitos que le plantean, y él es perfectamente consciente de esto: «[Y] teniendo yo el mando y el palo, haré lo que quisiere» (976). Por otra parte, la mención a la mano podría ocultar otra referencia autobiográfica a la manquedad del escritor. No por casualidad, estos guiños cervantinos están situados en momentos de la novela en donde se alude al acto de escribir, como en el caso, anteriormente analizado, del episodio de la escritura divina en la pared. Cervantes potencia así la asociación entre la escritura (la firma) y la ausencia (el miembro amputado).

13. Un estudio ciertamente interesante sería el de analizar los juicios de Sancho mediante la teoría de los actos de habla de John L. Austin y John Searle. El propio Walter Ong (170) señala la relación entre la concepción del lenguaje como acción, propio de las culturas orales, y la idea de la palabra como acto, sistematizada en How to do Things with Words y otras obras. 
dar traslado a la parte, sin autos, demandas ni respuestas; que todas las causas, si no son las matrimoniales, se despachan en pie y en un punto, más a juicio de buen varón que por ley alguna. Y entre aquellos bárbaros, si lo son en esto, el cadí es el juez competente de todas las causas, que las abrevia en la uña y las sentencia en un soplo, sin que haya apelación de su sentencia para otro tribunal (56).

Encontramos recogida exactamente la misma fórmula en lo que dice Sancho, cuando afirma que resolverá esa sentencia «a juicio de buen varón». Otro eco de este canto a la justicia musulmana puede encontrarse en El Viaje de Turquía, obra anónima escrita a mediados del siglo XVI, en la que se cuentan las peripecias de Pedro de Urdemalas, hecho prisionero por los turcos y llevado a Constantinopla, donde permaneció cautivo ocho años. En la obra, el protagonista compara la justicia española y la musulmana, y así, podemos leer: «La justicia del turco reconoce igualmente de todos, ansí christianos como judíos y turcos» ¿Y cómo administran justicia los musulmanes? Según Urdemalas, las audiencias se realizan «con toda la prontitud que pueden», no habiendo «pleitos de treinta y quarenta años como acá» (65). El calidesquer, como afirma Urdemalas que se llama en turco al juez, actúa siempre con gran celeridad, y el modo en que se llevan a cabo los procedimientos judiciales recuerda muchísimo al de los juicios en Barataria. «Si es cosa clara» comenta Urdemalas, «examina a los testigos, oye a las partes, y guarda justicia recta» (70). Resulta fácil comprender que Cervantes admirase este tipo de justicia, basada en la virtud natural, elogiada por Erasmo en sus Adagia, y que tanto se parece a la que el sagaz gobernador despliega en sus juicios ${ }^{14}$.

Sigamos con Sancho y sus sentencias ejemplares. En el segundo pleito, el del báculo y los escudos, el gobernador muestra una agudeza fuera de lo común, y así, cuenta el narrador que los circunstantes «quedaron todos admirados y tuvieron a su gobernador por un nuevo Salomón» (II, 45; 995). La referencia bíblica es obvia, se encuentra recogida en el Antiguo Testamento (Reyes 3.1628). Al preguntársele a Sancho cómo había logrado dilucidar el asunto, dice el escudero: «los que gobiernan, aunque sean unos tontos, tal vez los encamina Dios en sus juicios» y además «que él había oído contar otro caso como aquel al cura de su lugar, y que él tenía tan gran memoria, que a no olvidársele todo aquello de que quería acordarse, no hubiera tal memoria en toda la ínsula» (II,

14. Una opinión a tener en cuenta es la de Rodríguez Marín, para quien la decisión salomónica de Sancho debe emparentarse con las pésimas condiciones de los presos en las cárceles en la época:

«Con esta disparatada disposición burlesca se burló Cervantes de la frecuencia con que toda suerte de comisos aun en materia de abastos, y no ya por falta de peso, sino hasta por pésima calidad de los alimentos, se destinaban para los presos de la cárcel, cosa que con sobrada razón censuraba Castillo de Bobadilla en el lib. III, cap. IV de Politica para corregidores y señores de vasallos» $(15, \mathrm{n} 2 \mathrm{v} 7)$.

Es muy probable que Rodríguez Marín esté en lo cierto. Este trato inhumano dispensado a los presos al que alude dicho crítico, unido a lo dilatadísimo de las sentencias, hicieron que Cervantes admirase esta forma de impartir justicia de los musulmanes, que tanto se parece a la justicia de las culturas orales. 
45; 996). Lo primero remite de nuevo al concepto humanista de virtud natural, tan celebrada por los humanistas del siglo XVI: el hombre es capaz de discernir el bien del mal gracias a la sabiduría que Dios depositó en él. Asimismo, llama la atención la segunda aclaración de Sancho, al afirmar que fue capaz de averiguar el pleito porque «él había oído contar otro caso como aquel al cura de su lugar, y que él tenía tan gran memoria, que a no olvidársele todo aquello de que quería acordarse, no hubiera tal memoria en toda la ínsula» (II, 45; 996). Sancho emplea un mecanismo típico de las sociedades orales, donde los individuos aprenden escuchando y repitiendo el material oral legado por las generaciones que les precedieron. Sancho puede resolver el enigma porque ha oído contar la historia al cura de su pueblo, y la recuerda porque lo que le contaron tiene relevancia para él, ya que tiene una aplicación inmediata en un marco referencial. A esta característica, típica de los pueblos orales, se le ha dado el nombre de «homeostasis» ${ }^{15}$ (Ong 46). Estas sociedades, al carecer de escritura, deben seleccionar y conservar la información relevante y que pueda ser empleada en una situación «concreta», al tiempo que olvidan la que no es vital para su supervivencia o modo de vida ${ }^{16}$. Esto apunta al carácter práctico que la memoria tiene en las culturas orales: en éstas lo fundamental es que algo funcione. Por eso Sancho, con cierta socarronería, afirma que siempre se le olvida «todo aquello de que quería acordarse» (II, 45; 996). Lo que quiere decir con esta graciosa salida es que él no puede permitirse almacenar recuerdos que no tengan utilidad práctica. Ni él ni ningún miembro de su familia, los Panza, poseen libros - ¿para qué si no saben leer ni escribir? - a los que acudir cuando necesitan recordar algo. En las culturas orales, la memoria, esa «admirable virtud y facultad», como la llamó San Agustín, es un escaso elixir que hay que utilizar con sabiduría. En este sentido, es difícil imaginar una aplicación mejor que la que Sancho hace. No es de extrañar que el corrillo de servidores del duque se quede embelesado con el admirable proceder del gobernador: «los presentes quedaron admirados, y el que escribía las palabras, hechos y movimientos de Sancho no acababa de determinarse si le tendría y pondría por tonto o por discreto» (II, 45; 996).

El tercer pleito, el de la mujer supuestamente violada, Sancho lo resuelve de nuevo de manera salomónica. Como ya se apuntó, sus orígenes se remontan a la mujer violada del Norte de los estados de fray Francisco de Osuna. Por lo tanto,

15. «Oral societies live very much in a present which keeps itself in equilibrium or homeostasis by sloughing off memories which no longer have present relevance» (Ong 46).

16. Demasiado a la ligera, desde nuestras culturas tecnológicas presuponemos que las personas en las culturas orales disponen de capacidades memorísticas fabulosas. En los últimos años, investigadores como Walter Ong o Jack Goddy han puesto en tela de juicio esta idea un tanto ingenua, puesto que reduce de manera demasiado simplista la complejidad del asunto. Oigamos al segundo: «It is true that such societies are largely dependent on internal memory for transmitting culture [...] However, they do not remember everything in a perfect form, that is, verbatim, by heart» (74). Dicho investigador afirma haber conocido en entornos orales a individuos incapaces de ofrecer un explicación en detalle de cómo se desarrollan sus costumbres iniciáticas o funerarias. No obstante, luego pueden llevarlas a cabo sin contratiempo de ningún tipo. «When the ceremonies actually start, one act leads to another until all is done» (74). 
debe suponerse que al enfrentarles a este caso, Cervantes quiso que un personaje ágrafo triunfase sobre la escritura. ¿Cómo puede Sancho resolver este enigma tan peliagudo? Eric Havelock sostiene que el pensamiento lógico apareció en Grecia primero con la introducción de la tecnología del alfabeto y su paulatina interiorización, proceso que culminaría en la época griega con la obra de Platón. Este hecho hizo, según Havelock, que los conceptos se independizaran poco a poco de su marco de aplicación, esto es, se hicieron cada vez más abstractos ${ }^{17}$. El silogismo sería la culminación de este tipo de pensamiento abstracto, ya que en este no existe ningún tipo de referencia a una realidad externa. Por otra parte, James Fernández (1980) estudió la habilidad de personas iletradas para resolver silogismos, percatándose de que las personas que no han recibido educación formal «suelen ir más allá de la información suministrada en una frase o en un pensamiento dado» (cit. en Ong 126). Consecuentemente, al contrario del pensamiento analítico, típico de los silogismos, en los que la conclusión se deriva necesariamente de la premisa, en las culturas orales, para resolver un problema, se suele acudir a un conocimiento del mundo más amplio, que es ante todo «situacional», en la terminología de Ong. Este pensador recalca que el acertijo «belongs in the oral world. To solve a riddle, canniness is needed: one draws on knowledge, often deeply subconscious, beyond the words themselves in the riddle» (53). Es decir, que el conocimiento de estas culturas orales se basa en la experiencia y la observación minuciosa de la realidad, y esto es precisamente lo que hace Sancho para resolver el pleito. Si Sancho descubre la perfidia de la mujer es porque ha sospechado algo extraño en el comportamiento demasiado histriónico de la muchacha. La frase «aun eso está por averiguar, si tiene limpias o no las manos este galán» revela que los poderes discriminatorios de Sancho no se derivan del contenido semántico de las palabras de la joven, como se haría en un silogismo, sino de «algo» que va más allá. Este «algo» que hace sospechar al gobernador es la excesiva locuacidad de la joven, quien suelta un monólogo digno de una actriz de comedias:
Justicia, señor gobernador, justicia, y si no la hallo en la tierra, la iré a buscar al cielo! Señor gobernador de mi ánima, este mal hombre me ha cogido en la mitad dese campo y se ha aprovechado de mi cuerpo como si fuera trapo mal lavado, y, ¡desdichada de mí!, me ha llevado lo que yo tenía guardado más de veinte y tres años ha, defendiéndolo de moros y cris- tianos, de naturales y estranjeros, y yo siempre dura como un alcornoque, conservándome entera como la salamanquesa en el fuego o como la lana entre las zarzas, para que este buen hombre llegase ahora con sus manos limpias a manosearme (II, 45; 996).

Esta hiperabundancia de la palabra hablada se relaciona con lo que Marcel Jousse (1925) denominó «culturas verbomotoras», que son aquellas en las que las acciones y las actitudes hacia el mundo están fuertemente asociadas a la

17. Havelock demuestra cómo para los presocráticos la justicia se enmarcaba en un esquema más operacional y menos abstracto. Esta última noción se introdujo a partir de la revolución conceptual que supuso la irrupción del alfabeto y las vocales. 
palabra hablada y a la interacción humana. "All these peoples, wherever they still survive sheltered from our disassociating civilisation, speak fluently the figurative, symbolical, metaphorical language that we scarcely use anymore, except in [artificial writing, in] poetry or flowery literature» (énfasis mío, 4647). Por tanto, en estas culturas verbomotoras las personas muestran, además de una gran afluencia verbal - un exponente sería el propio Sancho-, un hablar rico en metáforas y comparaciones de todo tipo. Estas nociones son aplicables a la perorata dada por la prostituta, ya que, a pesar de su brevedad, es un buen ejemplo de este lenguaje altamente simbólico. La mujer emplea comparaciones, metáforas e hipérboles con el fin de recrear su historia y convencer al público que la escucha, utilizando un estilo sencillo pero muy metafórico y lleno de juegos verbales. La muchacha ha dado un amplio circunloquio verbal para decir algo que podría haberse expresado con escasas palabras. Pero es precisamente este lenguaje altamente retórico el responsable de que Sancho - a quien, no debe olvidarse, reprende don Quijote por no saber contener su habla - inmediatamente sospeche algo: se ha visto reflejado a sí mismo en los juegos retóricos de su interlocutor ${ }^{18}$. Además de la verbosidad y de lo figurado de su hablar, la entrada de la embaucadora en la sala nos informa de otro rasgo «verbomotor» asociado a las culturas orales. El narrador nos dice que la joven se acercó a los presentes «dando voces», es decir, haciendo que toda la atención de sus oyentes recayera sobre el volumen de su voz, lo que de nuevo apunta a la importancia que en las culturas orales tiene la dimensión verbal.

Por otra parte, debe mencionarse un factor que apunta sin ambages a la naturaleza oral/performativa de la muchacha, y que despierta las sospechas de Sancho: el alto componente somático que despliega la joven. Ong incide en este aspecto al ocuparse de los procesos mnemotécnicos en las culturas orales: «[O]ral memory has a high somatic componente [...] Spoken words are always modifications of a total, existential situation, which always engages the body» (énfasis mío 67). Berkley Peabody incide en el mismo punto, observando que en las culturas orales «From all over the world and from all periods of time... traditional composition has been associated with hand activity» (cit. en Ong, 120). El narrador dice que ésta entró en la sala «asida fuertemente de un hombre», lo que parece sugerir que la muchacha hacía aspavientos a la vez que gritaba desaforadamente. En otras palabras: para la joven lo corpóreo y lo cinético operan como prolongación de la palabra hablada.

18. Walter Ong también destaca esta recreación en la palabra hablada que se da en las culturas verbomotoras. «In primary oral cultures, even business is not business: it is fundamentally rethoric» (68). Ese carácter verbomotor de Sancho enoja profundamente al a veces taciturno Don Quijote, quien no puede concebir que alguien hable tantísimo como lo hace su escudero. Las continuas reprensiones del amo no logran aplacar la fogosidad verbal del escudero, quien sufre muchísimo cuando, a instancias de don Quijote, tiene que mantener la boca cerrada: «Señor don Quijote, vuestra merced me eche su bendición y me dé licencia, que desde aquí me quiero volver a mi casa y a mi mujer y a mis hijos, con los cuales por lo menos hablaré y departiré todo lo que quisiere; porque querer vuestra merced que vaya con él por estas soledades de día y de noche, y que no le hable cuando me diere gusto, es enterrarme en vida» (II, 45; 775). Como buen verbomotor, prohibirle la palabra a Sancho es despojarlo de su bien más preciado. 
En el capítulo LI le proponen un enigma al gobernador, mucho más difícil y sutil que los pleitos anteriores. Este enigma se asemeja mucho a las aporías, muy celebradas por los griegos. El enigma, conocido desde la Antigüedad, en realidad no puede resolverse mediante la lógica tradicional de forma satisfactoria, como ya expresó Bertrand Russell en su Introduction to Mathematical Philosophy. Su resolución significa la apoteosis de Sancho, que para resolverlo acude de nuevo a su virtud natural y al mecanismo de la «homeostasis». Sancho recuerda oportunamente los consejos que le dio Don Quijote, en particular aquél que le aconsejaba mansedumbre en la aplicación de la justicia. Al igual que en los otros pleitos, vemos una plasmación de la homeostasis. Sancho utiliza sabiamente este mecanismo típico de las sociedades orales, siendo capaz de aplicarlo en un caso práctico ${ }^{19}$.

Por otra parte, el significado de los juicios de Barataria tiene que ver con la percepción de un sistema de justicia injusto e ineficiente, un tema que ciertamente preocupó al Manco de Lepanto. Durante la época de Cervantes numerosos tratados recogieron esta preocupación. Por ejemplo, en su Memorial de la política necesaria (1600) González de Cellorigo criticaba la excesiva burocratización de la justicia durante la época de Cervantes. Para dicho arbitrista, la riqueza de un reino no se cifraba en sus ejércitos, su dinero o sus posesiones materiales. «La perfección de un reino», argumenta Cellorigo, «no consiste en la grandeza de estados, sino en la consistente y armoniosa justicia entre sus ciudadanos». Como es sabido, el Memorial estaba dirigido a Felipe II, quien se había esforzado por dotar al reino de un sistema de leyes justo y eficaz: «Procuró [Felipe II] restituir los estados con la ordenación de sus justas leyes al más seguro estado que ser pudo, sin dejar cosa que no hiciese ni ley que no renovase». Sin embargo, a juicio de Cellorigo, el Rey Prudente no consiguió su empeño, en un país en el que la ley que «un día salía a muy pocos no se guardaba» (97). Cellorigo incide en particular sobre el enorme número de pleitos, la mayoría por cuestiones triviales o por simple avaricia que se entablaban en las audiencias españolas, con no otro propósito «sino de coger las haciendas de sus vecinos» (167), hecho que evidentemente recuerda a la avaricia demostrada por varios de los litigantes en Barataria. Además, sólo dos décadas más tarde, otro arbitrista, Sancho de Moncada, en su Restauración Política de España (1619), incidía en los mismos puntos que Cellorigo:

«Los daños de tantas leyes» afirma Moncada, «son muchos. El primero, que oprimen el Reino (...) y no hay en el reino persona que las sepa todas, ¿cómo las ha de saber el labrador, y el ignorante, para guardarlas (...)? El segundo daño es que muchas de ellas no se usan, y dejan la puerta abierta a jueces para que aprieten a quien quisieren (...) El último y principal daño es que no se guardan, en desprecio de la autoridad de los legisladores, $\mathrm{y}$ gran perjuicio de la república» (201-201).

19. En opinión de Martín Morán, «Sancho no se rige por la palabra, sino por el dicho, por la frase, la sentencia, el proverbio. No es importante para él recordar la forma concreta de la palabra precisa. Lo que importa es el discurso completo, el saber que encierra y la posibilidad de aplicarlo en un momento dado» (352). 
En la misma línea que Moncada, Zevallos, abogado y regidor de Toledo, afirmaba de manera tajante en su Arte real para el buen gobierno que «Jamás se han visto tantos tribunales y menos justicia, tantos jueces y senadores y menos cuidado de la República, tantas leyes, abogados, escribanos, notarios y menos escuchada la causa del pobre» (125). Desde este punto de vista, los intrascendentales pleitos dirimidos por Sancho en Barataria tienen mucho que ver con el sobresaturado sistema judicial descrito por los arbitristas españoles. Barataria representa el triunfo de un tipo de justicia rápida y eficaz, asociado en la imaginación cervantina a la oralidad. Quizá por esa razón Cellorigo, al señalar la influencia que los ciudadanos de renombre ejercían en sus conciudadanos, citaba el caso del legislador Licurgo, quien ordenó «que las leyes no se pusiesen en escrito, y así nunca hubo leyes más fuertes, ni mejor guardadas, que las suyas» (100). En este contexto, no debe ser casualidad que el mayordomo diga de Sancho que «ni el mismo Licurgo, que dio leyes a los lacedemonios, no pudiera dar mejor sentencia que la que el gran Panza ha dado» (II, 51 1047). En medio de un imperio altamente burocratizado (y cuyo mejor ejemplo sería quizá la figura de Felipe II, el Rey Papelero) la isla de Barataria representa el triunfo de un tipo de justicia rápida y eficaz, como un último recurso de resistencia ante el poder de las clases altas y del ascenso y promoción de los letrados, proceso ampliamente documentado ${ }^{20}$.

Volviendo ahora a la afirmación de Chevalier, puede comprobarse que en Cervantes había un plan claramente preestablecido que tenía como fin el ensalzar la cultura oral de Sancho. Es difícil asentir con él en que «es extraño que triunfara la agudeza de Sancho en unas sentencias de índole erudita, en unos casos que mal podía conocer un analfabeto» (71). Sólo deben recordarse las palabras de Castro: «se pensaba que el genial artista era un producto de ocasionales aunque sublimes intuiciones; se ignoró siempre su formidable capacidad de elección» (384).

Sancho Panza triunfa en unas pruebas de agudeza ciertamente espinosas, que habrían sido motivo de escarnio para el más avezado gobernador. La cultura oral sanchopancesca irrumpe con fuerza en la obra de Cervantes y se yergue por derecho propio en la otra gran voz de la novela. Este es precisamente el dilema del Quijote: representa un mundo que se escinde entre lo oral y lo escrito. Libros, páginas y más páginas y un caballero que se vuelve loco leyendo. ¿Quién puede dudar que en Cervantes no haya todo un homenaje a la escritura? Cervantes, como Platón, recurrió a lo escrito —en forma de diálogo - para transmitir información. Cervantes no escatima elogios para la escritura: gracias a ella podemos reconstruir la límpida memoria oral que, irónicamente se perdió

20. Como es sabido, estos eran grupos pertenecientes a capas medias, educados en Derecho en universidades prestigiosas como Salamanca o París y solían trabajar como abogados principalmente en los Consejos o Audiencias. Alcanzaron especial protagonismo durante el reinado de Felipe II (Floristán Imízcoz, 291). 
por causa de la letra escrita. Así, a lo largo de las páginas de la novela cervantina dos voces conviven, una perteneciente al mundo de la escritura, simbolizada por el caballero, y la otra a la oralidad, encarnada por el escudero. Es innegable que Cervantes dignifica esta cultura popular, y hace que muchas veces prevalezca sobre la oficial: los juicios de Sancho son un ejemplo de esto. Sin embargo, sería inocente pensar que Cervantes pretendía volver a una etapa pretecnológica, oral. El que la oralidad se imponga en el Quijote en numerosas ocasiones ha de considerarse en un sentido más profundo: lo oral es el contrapunto necesario a lo escrito y oficial. Por esta razón Mikhail Bakhtin afirma que el Quijote es la primera novela moderna, puesto que muestra el mundo como algo pluriforme y dialógico. La novela cervantina simboliza mundos enfrentados y definitivamente irreconciliables, el antiguo y el moderno (ambos marcados por la nueva tecnología de la escritura) mediante dos voces: Sancho y Don Quijote.

\section{OBRAS CITADAS}

BAKHTIN, Michael, The Dialogic Imagination: Four Essays, ed. por Michael Holquist, Austin, University of Texas Press, 1981.

Biblia SaCra, Iuxta Vulgatam Versionem. Fischer, Bonifatius, and Robert Weber, eds. Tertia emendata ed., Stuttgart, Deutsche Bibelgesellschaft, 1983.

CAstro, AmÉRICO, El pensamiento de Cervantes, Madrid, Revista de Filología Hispánica, 1925 .

Cervantes, Miguel de, Don Quijote de la Mancha, ed. Francisco Rico, 2. ${ }^{a}$ ed., 2 vols + CD, Barcelona, Crítica, 1998.

Cervantes, Miguel de, Don Quijote de la Mancha, ed. Francisco Rodríguez Marín, 10 vols., Madrid, Atlas, 1947-1949.

Clanchy, Michael T., From Memory to Written Record: England 1066-1307, Bath, The Pitman Press, 1979.

Clermont-Ganneau, Charles Simon, «Mene, Tekel, Peres and The Feast of Belshazzar», Hebraica, 3, 2 (1887), 87-102.

Chevalier, Maxime, «Sancho Panza y la cultura escrita», Studies in Honour of Bruce W. Wardropper, Newark, Juan de la Cuesta, 1989, 67-73.

Chevalier, Maxime, Folklore y literatura: el cuento oral en el Siglo de Oro, Barcelona, Crítica, 1978.

Delgado Gómez, Ángel, «Una visión comparada de España y Turquía: El Viaje de Turquía», Cuadernos Hispanoamericanos: Revista Mensual de Cultura Hispánica, 444 (1987), 35-64.

FrenK, Margit, Entre la voz y el silencio: la lectura en tiempos de Cervantes, México, Fondo de cultura económica, 2005.

GÓMEZ ÁlvareZ, Ubaldo, Revisión histórica de la presión fiscal castellana, siglos XVIXVIII: Análisis tributario del caso de la província de León, sus partidos y concejos en el siglo XVII, Oviedo, Universidad de Oviedo, 1996.

GonzÁlez de Cellorigo y Pérez de AyAla, José Luis, Memorial de la política necesaria y útil restauración a la república de España y estados de ella y del desempeño universal de estos reinos (1600), Madrid, Instituto de Cooperación Iberoamericana: Quinto Centenario, Instituto de Estudios Fiscales, Ministerio de Economía y Hacienda, 1991. 
Goody, Jack, «Memory in oral Tradition», Memory, ed. Patricia Fara and Karalyn Patterson, Cambridge, Cambridge University Press, 1998, 73-94.

Havelock, Eric, Preface to Plato, $3^{\text {rd }}$ ed. Cambridge, Harvard University Press.

Jousse, Marcel, The Oral Style, Trans. Edgard Sienaert and Richard Whitaker, New York, Garland, 1990.

LORD, Albert, The Singer of Tales, Cambridge, Harvard University Press, 1960.

MARTín MorÁn, José Manuel, «Don Quijote en la encrucijada: Oralidad/escritura», Nueva Revista de Filología Hispánica, 45.2 (1997), 33-70.

MonCADA, Sancho de, Restauración política de España, ed. Jean Vilar, Madrid, Berrogain, 1973.

ONG, Walter J., Orality and literacy: the Technologizing of the word, London, New York, Methuen, 1982.

PARR, James A., «Plato, Cervantes, Derrida: Framing Speaking and Writing in Don Quixote», On Cervantes: Essays for L. A. Murillo, ed. James A. Parr, Newark, DE: Juan de la Cuesta, 1991, 163-187.

Rivers, Elias, Quixotic Scriptures: Essays on the Textuality of Hispanic Literature, Bloomington, Indiana University, 1983.

Percas de Ponseti, Helena, «Los consejos de Don Quijote a Sancho», Cervantes and the Renaissance, ed. M.D. McGaha, Newark, Juan de la Cuesta, 1980, 194-236.

REDONDO, Augustin, «Tradición carnavalesca y creación literaria, del personaje de Sancho Panza al episodio de la Insula Barataria en el Quijote», Bulletin Hispanique, 80 (1978), 39-70.

SchAma, Simon, Rembrandt's eyes, New York, Random House, 1999.

Zimmermann, Frank, «The Writing on the Wall: Dan. 5.25 f», The Jewish Quarterly Review, 55 (1965), 201-207.

Recibido: 20 de enero de 2010

Aceptado: 9 de junio de 2010

\title{
Resumen
}

Este estudio examina las relaciones entre la oralidad y la escritura en el episodio de Barataria, en la Segunda Parte de Don Quijote. Propone que los sabios juicios de Sancho en Barataria son un ejemplo de la supremacía de la oralidad sobre la escritura en esta novela. En particular, cómo Cervantes usa la oralidad y sus marcas como una herramienta para denunciar el excesivamente burocratizado sistema judicial de su época.

Palabras clave: Don Quijote. Barataria. La Biblia. Sancho. Oralidad. Escritura. Burocracia.

Title: Barataria, a Crossroads: Between Orality and Writing.

\begin{abstract}
This study examines the interrelations between orality and literacy in the episode of Barataria, in the Second Part of Don Quijote. It proposes that Sancho Panza's wise judgments in Barataria are an example of the supremacy of orality over writing in this novel. Specifically, how orality is used by Cervantes as a device to denounce the excessively bureaucratized judiciary system of his time.
\end{abstract}

Key words: Don Quijote. Barataria. The Bible. Sancho. Orality. Writing. Bureaucrazy. 